\title{
Trajetórias de mulheres atuantes em pequenos abatedouros de animais
}

\author{
Laila Priscila Graf ${ }^{1}$ e Maria Chalfin Coutinho ${ }^{2}$ \\ Programa de Pós-Graduação em Psicologia da Universidade Federal de Santa Catarina
}

\begin{abstract}
Este estudo discute os resultados de uma pesquisa sobre o trabalho de três mulheres na produção de carne, a partir das trajetórias identitárias. Esta análise fundamenta-se no entendimento da história pregressa do trabalho, no presente e nos projetos futuros. As participantes da pesquisa foram três mulheres que trabalhavam em dois pequenos abatedouros de animais com características rurais. Para a coleta das informações, foram realizadas entrevistas com as trabalhadoras e observações no campo, bem como feita a análise de documentos sobre a produção de carne. Os resultados foram organizados em três categorias temáticas: olhar para o passado, entre ser trabalhadora e ser proprietária de um abatedouro e projetos profissionais. Foi possível identificar que as vivências anteriores das entrevistadas estavam articuladas com a produção da carne como alimento para autoconsumo e como forma de subsistência econômica familiar. Evidenciou-se que as práticas cotidianas do trabalho foram marcadas pelas possibilidades e restrições educacionais das entrevistadas. A respeito do projeto profissional, houve destaque na permanência das trabalhadoras nos abatedouros com anseios de exercerem outras atividades.
\end{abstract}

Palavras-chave: Trajetórias ocupacionais, Produção de carne, Abatedouros, Trabalho de mulheres, Mulheres rurais, Agroindústrias.

Trajectories of women working in small slaughterhouses of animals

This study discusses the results of a research of the work of women in meat production, with the analysis of their trajectories identity. This analysis is based on the history of women's work in the present and its future projects. The participants of the research were three women who worked in two small slaughterhouses of animals, with rural characteristics. For the purchase of information, interviews were conducted with workers and observations in the field, as well as analysis of documents on the production of meat. The results were organized into three thematic categories: look to the past, between being worker and be the owner of a slaughterhouse and the future professionals. It was possible to identify earlier experiences of the interviewees articulated with the production of meat as food and as a means of subsistence family. It was proven that the daily practices of work were marked by the educational possibilities and restrictions of the interviewees. With respect to the future professional there was prominent in the permanence of workers in the slaughterhouses with aspirations to pursue other activities.

Keywords: Occupational trajectories, Meat production, Slaughterhouses, Women's work, Rural women, Agroindustries.

\section{Introdução}

E ste artigo apresenta uma análise sobre as trajetórias de mulheres atuantes na produção de carne, locadas em dois pequenos abatedouros de animais na microrregião de Blumenau, Santa Catarina. Foram investigadas as histórias de três mulheres inseridas nesse tipo de atividade produtiva com o objetivo de analisar os sentidos dados por elas ao passado, ao presente e ao futuro profissional. A análise fundamentou-se nas trajetórias identitárias, uma estratégia de investigação proposta por Coutinho (2009) e Soares e Sestren (2007), a partir do desdobramento dos métodos das formas identitárias de Dubar (1998) e das trajetórias sociais apresentadas por Gaulejac (2005).

\footnotetext{
1 Mestranda do Programa de Pós-Graduação em Psicologia da Universidade Federal de Santa Catarina.

2 Professora do Departamento e do Programa de Pós-Graduação em Psicologia da Universidade Federal de Santa Catarina.
} 
A investigação das trajetórias das mulheres em foco neste estudo permitiu compreender o contexto dos pequenos produtores de carne inseridos em municípios de menor porte, como também observar as oportunidades de trabalho para mulheres de localidades semirurais. Este texto objetivou contribuir para as discussões das relações de trabalho dentro do setor econômico produtivo da carne, por meio da análise das trajetórias ocupacionais das mulheres atuantes em pequenos abatedouros.

O interesse em pesquisar esse setor produtivo decorreu da participação da primeira autora em dois projetos de pesquisa. Um deles sobre ética e desenvolvimento regional, com a investigação dos interesses de humanos e não humanos em abatedouros na microrregião de Blumenau (SC), cujos resultados possibilitaram a construção de um banco de informações sobre a produção de carne e o abate (Florit, Teixeira, Chaves \& Graf, 2006). O segundo projeto foi referente à atuação profissional de mulheres em abatedouros de pequeno porte, com foco na dimensão psicológica e social das trabalhadoras (Graf \& Silva, 2006). Ambas as pesquisas subsidiaram o desenvolvimento deste manuscrito com informações sobre o campo e na identificação das participantes.

Tendo em vista o objetivo deste artigo em discutir a trajetória ocupacional de trabalhadoras no contexto produtivo da carne, são apresentados a seguir os conceitos de formas identitárias, trajetórias sociais e trajetórias identitárias. Em um segundo momento, são descritos o contexto da produção de carne e suas implicações socioeconômicas para o país, para Santa Catarina e para a microrregião de Blumenau. Posteriormente, são relatadas as trajetórias das participantes, as discussões e as considerações finais.

\section{Trajetórias ocupacionais}

\section{Abordagens para a investigação de trajetórias ocupacionais}

Em primeiro lugar, este artigo enfatizará as compreensões teóricas de Dubar (1998) e Demazière e Dubar (2006). No primeiro trabalho, o autor ressaltou dois modos de entender as trajetórias individuais. De um lado, a trajetória objetiva, que seriam os lugares sociais nos quais os sujeitos vão transitando no percurso de suas vidas e, de outro lado, a trajetória subjetiva, que corresponderia aos modos dos sujeitos discursarem sobre suas vidas.

De acordo com Dubar (1998), as trajetórias objetivas são produzidas por meio de um acesso às sequências de posições em um ou mais campos da prática social, como exemplo, o percurso escolar ou profissional. Essa análise consiste em perceber elementos comuns nos itinerários dos sujeitos a ponto de identificar traços semelhantes e, a partir disso, ir construindo categorias descritivas sobre os relatos apresentados. $\mathrm{O}$ autor também registrou a necessidade de interpretar e ordenar as trajetórias em termos de mobilidades sociais, para que um itinerário possa ser analisado sociologicamente como classes de trajetórias típicas, existindo um significado teórico e uma representatividade empírica. Esse processo constituiria "uma análise objetivista das trajetórias na medida em que não se leva em conta o sentido subjetivo que os indivíduos atribuem ao próprio percurso" (Dubar, 1998).

O segundo modo de entender o processo biográfico é a partir das trajetórias subjetivas. Conforme Dubar (1998), esse aspecto compreenderia os relatos sobre vivências e experiências pessoais. A importância estaria na verbalização dos percursos vividos, formando discursos e narrativas que envolvem visões de si e do mundo ao redor. Desse modo, as trajetórias subjetivas são fundamentalmente os relatos biográficos feitos pelos sujeitos, pois, no momento que os sujeitos narram suas vidas, há uma tentativa de construírem relatos relacionados com os 
contextos históricos e sociais correspondentes. Em outras palavras, os sujeitos não apenas discorrem sobre suas vidas, mas também sobre os acontecimentos no entorno e, assim, é possível analisar os fatos sociais que dialogam com as histórias pessoais. Uma narrativa que pode ser identificada a partir de uma situação de entrevista, como a praticada nesta pesquisa (Demazière \& Dubar, 2006).

Outra perspectiva da análise das trajetórias foi desenvolvida por Gaulejac (2005). Esse autor compreendeu o sujeito a partir do entrelaçamento entre o social e o psíquico, considerando o ser humano a partir de sua história, nos momentos de rupturas e nos casos de continuidades entre o presente, o passado e o futuro; uma abordagem de característica processual. "As relações entre indivíduos e sociedade se inscrevem na historicidade, isto é, na capacidade de se inscreverem num passado e se projetar num futuro diferente do presente" (Gaulejac, 2005, p. 68).

Indicar as inter-relações entre a psique e o social foi um dos objetivos Gaulejac (2005), assinalando que a maneira de compreender o ser humano inicia-se pela análise dos diferentes modos de construções sociais dos sujeitos para, assim, efetuar uma sociologia do sujeito. De acordo com o autor, é necessário estudar rupturas, complementaridades, influências, continuidades e outros aspectos do percurso pessoal de cada sujeito para entender a unidade dos seres humanos. Como, inclusive, analisar os processos sociais conjugados com os pessoais, de modo que o sujeito se construa na intersecção de quatro diferentes registros: a) no universo cognitivo da reflexividade, no qual a pessoa reflete sobre o mundo em que vive; b) no universo de leis, regras, normas, valores éticos e morais; c) a partir do universo do inconsciente, das pulsões, fantasias, o lugar do sujeito de desejo; d) nos intercursos do universo e da sociedade, nos espaços sociais, espaços culturais e institucionais das relações sociais. $\mathrm{O}$ autor esclareceu que o mapeamento dessas quatro referências produz um conhecimento sobre as trajetórias pessoais, possibilitando conhecer os lugares físicos, psíquicos e sociais vivenciados.

A efetuação da articulação entre as formas identitárias e as trajetórias sociais caracterizam as trajetórias identitárias. Coutinho (2009) indicou o uso das trajetórias identitárias como uma estratégia de investigação dos sentidos do trabalho. A autora discorreu sobre as mudanças recentes no mundo do trabalho que acarretaram transformações significativas nas relações concretas dos seres humanos, destacando a necessidade de haver ampliação das investigações sobre os trabalhadores em diferentes situações e contextos. Esclareceu como o uso das trajetórias identitárias possibilitaria um caminho para compreender as experiências de trabalho na contemporaneidade. Soares e Sestren (2007) também empregaram a reflexão das trajetórias identitárias em sua pesquisa enfocando a inter-relação entre projeto parental e o projeto pessoal, investigando a influência da família na consolidação de projetos pessoais. Segundo as autoras, uma análise das trajetórias permite compreender o quanto heranças influenciam as escolhas atuais nos aspectos social, profissional, amoroso, econômico e outros.

\section{Procedimentos de investigação das trajetórias identitárias}

Coutinho (2009) e Soares e Sestren (2007) apresentaram as trajetórias identitárias em uma perspectiva de integração entre as formas identitárias propostas por Dubar (1998) e as trajetórias sociais concebidas por Gaulejac (2005). O enfoque da presente investigação priorizou a dimensão temporal, tornando-se relevante a investigação de passado, presente e projeto da vida laboral dos sujeitos de pesquisa. Ao enfocar a dimensão temporal das trajetórias ocupacionais, este estudo inseriu-se em uma abordagem qualitativa de pesquisa, uma escolha compreendida como ênfase e não como oposição ao quantitativo (Alves, 1991).

Os sujeitos participantes desta pesquisa foram três trabalhadoras atuantes na produção de carne, locadas em dois estabelecimentos familiares de pequeno porte, situados em dois 
municípios da microrregião ${ }^{3}$ de Blumenau, SC. Os procedimentos de coleta das informações foram entrevistas semiestruturadas e a observação no campo. Duas entrevistas foram gravadas e transcritas e a outra foi somente registrada em diário de campo. Para complementar as informações, também foram analisados documentos sobre a produção de carne brasileira e catarinense. Os documentos consultados foram os registros sobre os estabelecimentos de abate de médio e pequeno porte situados no arquivo do Grupo Interdisciplinar de Pesquisa sobre Desenvolvimento e Meio Ambiente ${ }^{4}$.

O principal instrumento de pesquisa foi a entrevista feita in loco com as trabalhadoras. Foi empregado um roteiro com perguntas norteadoras, organizadas em diferentes temáticas sobre as trajetórias de trabalho. Com esse procedimento, não se objetivou respostas precisas, mas sim, conduzir uma conversa com as participantes para atender aos objetivos da pesquisa. Alves (1991) assinalou que nas pesquisas qualitativas as entrevistas devem procurar se assemelhar mais a conversas. Zago (2003) indicou o uso de entrevistas como meio de fomentar um diálogo entre duas pessoas, em que a proximidade entre o pesquisador e o informante deve possibilitar uma fala livre sobre a vida cotidiana. A autora inclusive esclareceu o caráter indissociável entre a entrevista e a observação, especialmente quando feitas nos espaços de circulação ou residência, por facilitarem a conversa, como também por possibilitarem conhecer as condições sociais e econômicas das famílias, tal como ocorreu nesta investigação.

O procedimento de análise do material foi fundamentado na análise das trajetórias identitárias das participantes, identificando as dimensões de passado, presente e futuro (Coutinho, 2009). Os achados foram organizados em três grandes categorias temáticas, cada uma com subcategorias. O olhar para o passado engloba: primeiros contatos com a atividade de abate; escolaridade e suas influências no trabalho e outras ocupações remuneradas. Caminhar no presente divide-se em duas subcategorias: entre ser trabalhadora e ser proprietária de um abatedouro e cotidiano do trabalho. Já a última categoria, pensar o futuro, diz respeito aos projetos profissionais das entrevistadas.

\section{Contexto da pesquisa}

O contexto no qual se insere esta pesquisa é o da bovinocultura de corte e da produção de carne. O gado começou a ser domesticado há mais de 6 mil anos, servindo como transportador de carga, fornecendo leite, couro e carne. $O$ fornecimento da carne nesse período não era a principal razão da criação de animais bovinos. No Brasil, a bovinocultura iniciou-se no período colonial, quando os portugueses trouxeram os animais nos navios para consumo e transporte, mas somente nos séculos XVIII e XIX houve um crescimento significativo dos rebanhos (Sarcinelli, Venturini \& Silva, 2007).

Mediante a ascendência desse crescimento, a partir de meados do século XX, o Brasil se tornou um produtor reconhecido internacionalmente como um dos maiores fornecedores de carne bovina do mundo (Ferraz \& Figueiredo Jr., 2003). Nos últimos trinta anos, a partir da década de 1980, a pecuária de corte brasileira apresentou recordes de exportação e produção de carne (Embrapa Gado de Corte, 2007). Tornando-se atualmente, em 2008, o detentor do maior rebanho comercial bovino do mundo e o principal produtor de carne bovina no comércio internacional (Instituto Brasileiro de Geografia e Estatística, 2008a).

Na produção de carne, existem os estabelecimentos pertencentes ao setor primário, atrelado às atividades agropecuárias, ou vinculados ao setor secundário, como indústria de

3 Essa microrregião compreende dezesseis municípios no estado de Santa Catarina.

4 Grupo integrado ao Programa de Pós-Graduação em Desenvolvimento Regional, coordenado pelo prof. Luciano Félix Florit, da Universidade Regional de Blumenau. 
transformação (Classificação Nacional de Atividades Econômica, CNAE, 2006). Os pequenos abatedouros estudados aqui são associados ao setor primário, integrando atividades de cultivo agrícola, criação animal, como as de abate dos animais.

A comercialização dos produtos derivados da produção bovina é dependente do tipo de inspeção sanitária à qual o estabelecimento está atrelado. $O$ tipo de inspeção sanitária determina a circulação dos produtos, se um estabelecimento é vinculado a uma inspeção sanitária federal pode comercializar em todo território nacional e efetuar a exportação. Nos estabelecimentos com inspeção municipal - como são os abatedouros estudados -, somente é possível a comercialização na mesma cidade. De acordo com o IBGE (2008a), há supremacia dos estabelecimentos de inspeção federal que, com menos empreendimentos, abatem quase $80 \%$ dos animais, de modo que os pequenos concorrem apenas com 6,7\% dos abates (IBGE, 2008a).

Como mencionado, foram estudadas as trabalhadoras atuantes em dois pequenos estabelecimentos de Santa Catarina. Esse estado é o décimo quinto produtor nacional de carne bovina e, por isso, não consta entre os principais estados produtores (IBGE, 2008a). No entanto, em 2008, instituições do setor produtivo assinalaram uma tendência de expansão dessa produção - pelo estado ser livre da febre aftosa, pelos avanços tecnológicos feitos em Santa Catarina, pela tendência de áreas de pastagens serem substituídas por cana-de-açúcar em estados com intensa produção e pelas restrições da pecuária na Amazônia (Abrafrigo, 2008).

Santa Catarina, tal como observara Paulilo e Schmidt (2003), ainda é conhecida por uma imagem associada à agricultura familiar, com uma estrutura mais pautada nos minifúndios em comparação com as grandes propriedades agrárias de outros estados. Visualizando o território catarinense, os autores assinalaram que mesmo ocorrendo, a partir dos anos 1970, um encaminhamento da população para os centros urbanos, é possível observar atualmente uma predominância de cidades médias e pequenas, com uma população próxima de práticas rurais e economia procedente da agropecuária. Ao discorrer sobre a formação econômica catarinense, Goularti Filho (2007) destacou o processo de migração ocorrido no estado, com a imigração alemã e italiana em maior proporção, contribuindo para as características comerciais de Santa Catarina serem pautadas predominantemente por atividades de médio e pequeno porte.

Estudando famílias rurais catarinenses, mais especificamente, uma região de colonização europeia próxima a microrregião de Blumenau, Cazella e Alves (2004) observaram a existência de diferentes atividades produtivas realizadas, além das agrícolas. As famílias integravam atividades não agrícolas remuneradas com atividades diversas relacionadas à produção agropecuária: comercialização dos produtos, vendas direta dos produtos, agroturismo. Também recebiam renda pela prestação de serviços, aposentadoria rural, bolsa escola. Essa realização de múltiplas atividades na propriedade se caracterizava como multifuncionalidade. Paulilo e Aued (2004) salientaram a relevância do tema, visto que em muitas propriedades, notadamente as catarinenses, há participação da renda de diferentes atividades coexistindo com a produção de autoconsumo. 


\section{Descrição das Trajetórias}

\section{Trajetória de Cristina ${ }^{5}$}

Cristina trabalhava na empresa de abate, com seu marido e filha, ao mesmo tempo proprietários e trabalhadores. A produção dessa pequena propriedade girava em torno do abate de 40 suínos e 32 bovinos mensais, excepcionalmente havia, também, o abate de ovelhas. $\mathrm{Na}$ propriedade eram feitas atividades de criação de animais, procedimentos de abate, defumados, embutidos e cultivo de arroz e milho, bem como o comércio dos produtos no próprio local.

O abatedouro foi inaugurado em 2002, construído na propriedade da família, localizada a uma distância de treze quilômetros do centro da cidade. Três trabalhadores atuavam nesse estabelecimento: o Sr. José, realizando todas as atividades produtivas, com a idade de 55 anos e o ensino fundamental incompleto, sua esposa e a filha Valéria. Aqui será comentado a trajetória de Cristina e, adiante, a de Valéria.

Cristina, é casada, tem 49 anos, não concluiu a quarta série do ensino fundamental, tem quatro filhas. Nasceu no mesmo município em que mora. Durante a entrevista, mencionou não ter tido tempo para estudar quando criança, pois precisava se dedicar aos trabalhos domésticos. Também relatou seu interesse por trabalhos de limpeza e relacionados com a água. Suas experiências anteriores de trabalho são todas relacionadas às atividades domésticas e ao abate de animais.

No estabelecimento da família, não existiam outros trabalhadores contratados, eventualmente um irmão era convidado para auxiliar na produção quando havia maiores demandas, como nas festas de final de ano. Em relação à família, as três outras filhas, exceto Valéria, trabalhavam em uma empresa têxtil e auxiliavam o trabalho dos pais nos serviços de limpeza. Essa atividade é realizada aos finais de semana, feita por todas as filhas. Relatou, ainda, que, quando há festas de igreja, eles são contratados para preparar e comercializar churrasco.

\section{Trajetória de Valéria}

Váléria, 23 anos, é uma das filhas de Cristina, a única que trabalha no abatedouro junto com os pais. É uma das gêmeas, mas sua mãe aponta que ela é a mais nova, pelo motivo de ser a "miúda" da família. É solteira, reside com seus pais. Estudou até a oitava série, concluindo o ensino fundamental. Iniciou suas atividades profissionais no abate, trabalhando junto com seus pais, mas também atuou em duas outras empresas.

A entrevistada relatou gostar do trabalho no abatedouro, por ser um espaço próximo a sua residência e por ser uma forma de auxiliar a seus pais. Assim pode evitar que eles se submetam às condições climáticas nem sempre favoráveis ao executarem as atividades agrícolas.

Sobre as atividades no abatedouro, Valéria mencionou realizar todos os tipos de serviços necessários: buscar animais para o abate nas propriedades de outros agricultores, a insensibilização de animais, o abate, os cortes, a embalagem e o transporte das carnes para o congelamento. Destaca os cuidados de higiene necessários para manter a qualidade do produto. Apesar de reconhecer as dificuldades inerente ao seu cotidiano de trabalho, prefere este a outros por não necessitar receber ordens.

5 Os nomes informados nesse trabalho são fictícios, com o objetivo de preservar as identidades dos trabalhadores, pelo mesmo motivo também não foram identificados os estabelecimentos nem os nomes dos municípios. 


\section{Trajetória de Helena}

Helena trabalhava em outro abatedouro, inaugurado em 1988, sendo também a proprietária junto com seu marido. Na empresa, eram abatidos mensalmente em média trinta bovinos e quinze suínos, as atividades realizadas eram as produções de carnes, defumados e embutidos. As carnes eram comercializadas no estabelecimento e no âmbito municipal.

O estabelecimento contava com cinco trabalhadores: o proprietário, Helena, o filho do casal e dois homens aposentados contratados como diaristas. $O$ proprietário tinha 47 anos, estudou o ensino médio completo e realizava todas as atividades produtivas, compartilhado suas horas entre o abatedouro e o emprego na prefeitura da cidade.

Helena era mãe de dois filhos, tinha 38 anos e concluiu o ensino médio técnico em contabilidade. Para cursar o ensino médio, precisou sair da localidade onde residia porque não havia esse nível escolar. O filho do casal, com 15 anos, cursava o ensino fundamental e desenvolvia todas as atividades produtivas.

A entrevistada relatou que o abatedouro foi criado em decorrência da necessidade de produzirem carne para o supermercado da família. Sua atuação no negócio foi facilitada por conhecer o processo de abate anteriormente. Como filha de agricultores, desde criança, Helena já auxiliava nas atividades de seus pais. No abatedouro suas atividades eram: gerenciar, comercializar e efetuar os cortes das carnes, bem como a limpeza e conservação do estabelecimento. Durante a entrevista foi possível observar que a casa de Helena é de dois andares, sendo que a residência da família é localizada no segundo piso e o abatedouro, no térreo.

\section{Análises das trajetórias ocupacionais: olhar para o passado}

\section{Primeiros contatos com a atividade de abate}

As três entrevistadas iniciaram no "mundo" do trabalho aprendendo as atividades de abate e o processo de fabricação dos produtos da carne por meio da convivência com seus familiares. A produção da carne adentrou as vidas das trabalhadoras de forma gradual, com uma passagem cotidiana de conhecimentos familiares. Esses conhecimentos adquiridos eram empregados nas suas atuais ocupações.

Ao investigar trabalhadores rurais atuantes no cultivo de arroz irrigado, Stolf (2007) observou ser a agricultura uma profissão que passa de pai para filho, iniciada já na infância, através do convívio em propriedades familiares. As mulheres neste estudo também apresentaram um início profissional antecipado e propiciado pelas atividades de seus familiares. "Eu aprendi tudo com meu pai, a trabalhar assim, a derreter banha, fazer linguiça [...], eu trabalhei assim com quatorze anos, acompanhando o pai, indo junto nas casas" (Cristina).

Valéria e Helena também iniciaram precocemente no exercício das atividades de abate. Valéria começou a trabalhar por volta dos quatorze anos participando das atividades laborais de abate de sua família. Helena esclareceu que iniciou no trabalho auxiliando nas atividades domésticas não-remuneradas e na agricultura familiar junto com seus irmãos. Na família de Helena, o processamento da carne era o principal modo de conservá-la pela ausência de refrigeradores. 


\section{Escolaridade e suas influências no trabalho}

As entrevistadas em geral tiveram pouco acesso à escolaridade. Cristina não concluiu a quarta série, Valéria concluiu o ensino fundamental sem poder continuar seus estudos pela necessidade de trabalhar e por não haver ensino médio na localidade. Helena realizou o ensino técnico em contabilidade e, para isso, necessitou se deslocar a outro município. Ney (2006) mencionou que a desigualdade de oportunidades em relação à escolaridade existe em todo território brasileiro, mas esclarece ser mais preocupante em localidades rurais, especialmente pelo acesso à escola ser mais difícil. A evasão em localidades rurais se inicia na primeira série escolar e é elevada em todo ensino fundamental. Os relatos das entrevistadas desta pesquisa reiteraram o assinalado por Ney (2006), pois duas não conseguiram acessar um maior grau de escolaridade e uma necessitou sair da localidade para efetuar o ensino médio.

A gente não tinha tempo de estudar, né [risos]. Até ontem, eu disse para minhas meninas, elas só tomavam o café e iam para aula. Eu tinha que varrer, nós antigamente tínhamos que varrer todo o pátio, tirar leite, fazer todo o serviço e depois a gente ia para aula [...]. Daí a gente não ia para aula para estudar, assim, a gente estava mais cansado, e eu gostava mais de desenhar, brincar (Cristina).

As entrevistadas necessitaram trabalhar na agricultura e em atividades domésticas desde a infância, o que dificultou seus processos de escolarização. De acordo com Kassouf (2007), embora alguns estudos considerem a possibilidade de crianças e jovens estudarem e trabalharem ao mesmo tempo, a maioria assinala que o trabalho exercido na infância impede a aquisição da educação formal e de aprendizados geradores de valores futuros para outros empregos. Para o autor "... quanto mais jovem o indivíduo começa a trabalhar, menor é o seu salário na fase adulta da vida e essa redução é atribuída, em grande parte, à perda dos anos de escolaridade em razão do trabalho na infância" (p. 343). No caso das participantes do presente estudo, o trabalho infantil, particularmente para Valéria e Cristina, gerou limitações quanto às oportunidades de empregos em postos com maior qualificação e melhores remunerações.

Helena, após um período de estudos, retornou a sua localidade, tendo se inserido nas atividades familiares com seu esposo. Uma tendência diferente da observada por Stropasolas (2006), que assinalou que grande parte das moças que saem de suas localidades rurais para estudar não regressam às suas comunidades de origem e, até mesmo, evitam o casamento com filhos de agricultores para não retomarem a condição social de agricultoras. Uma condição marcada por trabalhos ininterruptos, com pouco tempo livre disponível.

\section{Outras (poucas) opções remuneradas}

As três entrevistadas da pesquisa assinalaram efetuarem mais trabalhos dentro do contexto familiar do que atividades assalariadas. Cristina sempre trabalhou no âmbito doméstico, na produção agrícola e no abate de animais, bem como nos serviços domésticos nãoremunerados. Helena desenvolveu atividades domésticas remuneradas, prestou serviços de digitação em uma organização financeira, foi auxiliar no mercado da família e no abatedouro. Valéria atuou em indústria de confecção, madeireira e nos serviços da propriedade da família.

Ao analisar o mercado de trabalho brasileiro, o IBGE (2008b) constata a manutenção das mulheres em piores índices de inserção formal em relação aos homens. Bruschini (2007) reforça esse entendimento salientando o predomínio de mulheres das camadas populares em atividades informais e precárias. De acordo com a autora, as mulheres permanecem na atualidade em ocupações femininas consideradas tradicionais, tais como, na indústria de confecção, no auxílio de contabilidade e caixas, saúde e educação. 
Os trabalhos domésticos não-remunerados eram efetuados pelas três entrevistadas, feitos em um continuum entre o produtivo e reprodutivo (Hirata, 2002). Cabe observar, tal como coloca Paulilo (2004), que no âmbito rural não existe uma diferenciação entre as atividades produtivas e reprodutivas, pois aquilo que uma trabalhadora produz pode ser consumido pela família ou comercializado.

\section{Análises das trajetórias ocupacionais: caminhar no presente}

\section{Entre ser trabalhadora e ser proprietária de um abatedouro}

Foi possível observar a preferência das trabalhadoras pelo trabalho no abatedouro em relação a outros, especialmente pelas entrevistadas serem as proprietárias. "Também agora estou gostando de trabalhar aqui, é meu, porque trabalhar na roça, ou trabalhar na malharia para ser empregado, né, prefiro aqui cem vezes" (Cristina). De acordo com Frigotto (2002), é comum confundir com capitalista alguém que possui alguma propriedade de que retira sua sobrevivência, mas esclarece ser diferente, pois, mesmo sendo proprietários dos meios de produção, essas pessoas não exploram outrem para acumulação de riqueza e capital. Valéria relatou a diferença entre ser trabalhadora assalariada e ser proprietária:

... trabalhei dois anos em uma malharia, minhas irmãs também trabalham em uma malharia, só que eu não troco, eu não saio daqui para trabalhar em uma malharia. Aqui eu trabalho quando eu quero, não é? É apurado, é difícil ficar parada, mas aqui a gente é dono da gente (Valéria).

$\mathrm{Na}$ indústria, havia a extração da mais-valia do trabalho, Valéria era submetida à exploração do capital, tal como mencionado por Frigotto (2002), quando se referiu à profunda relação desigual entre o comprador da força de trabalho e o trabalhador. Valéria, como proprietária dos seus meios de produção, pode organizar seu trabalho e permanecer com o valor agregado por sua atividade.

Outro aspecto relacionado com o ser proprietária foi observar que a vida das três entrevistadas estava relacionada com a história do abatedouro. As três trabalhadoras relataram, com maior ou menor intensidade, a mudança de uma condição de vida agrícola para a consolidação do pequeno estabelecimento rural.

Os dois estabelecimentos em que se inseriram as entrevistadas surgiram a partir de uma iniciativa dos agricultores em potenciar uma atividade pertencente ao quadro da produção agropecuária familiar. De Grandi (2003) aponta a existência de cursos profissionalizantes na área da indústria rural no estado de Santa Catarina para o aproveitamento dos produtos agropecuários elaborados nas propriedades familiares, possibilitando a diversificação na alimentação da população rural e uma renda extra com a produção excedente. A autora ressaltou a dificuldade em adequar as propriedades caracterizadas por uma tradição artesanal às exigências da vigilância sanitária e o controle de qualidade dos alimentos, especialmente no trabalho com produtos de origem animal, fato que também se verificou no relato das entrevistadas. "Era tudo bonitinho, com forro e tudo, mas eles não aceitaram" (Cristina). As dificuldades foram relativas não só ao nível de exigência, mas também em relação aos custos implicados: “... avisaram nós, mas como nós não tínhamos como construir, daí multaram, jogamos fora um boi, daí começamos a construir, mas isso tudo, por certo, era o material para fazer a nossa casa" (Cristina). 
De Grandi (2003) ressaltou terem sido os próprios agricultores os que buscaram alternativas de produção dentro da agricultura familiar no intuito de viabilizar a propriedade familiar, gerando mais renda e empregos. No caso das entrevistadas, o caminho para a atividade de abate decorreu da necessidade financeira e por incorporar, através de empregos, mais integrantes da família. No entanto, esse caminho não foi estabelecido sem dificuldades para os agricultores, como apontou Stropasolas (2006), indicando que um agricultor não se transforma de um dia para o outro em um empresário industrial nem torna seus filhos e parentes trabalhadores industriais com a mesma agilidade.

\section{Cotidiano do trabalho}

O cotidiano do trabalho é compreendido a partir da leitura de Sato (2007), tendo em vista o fato de as pessoas incorporarem processos sociais dos lugares onde participam. Esses processos compreendem os sujeitos em suas ações cotidianas imbricadas com regras, valores e projetos com amplitudes coletivas e sociais. Nesse sentido, ao analisar o cotidiano de trabalhadores de feiras livres, considerando sua participação em redes sociais, a autora afirma: "A amplitude dessa rede alarga-se para diversos lugares além daqueles nas quais as feiras livres se instalam e se corporifica no chão do cotidiano por meio de conversas entre vizinhos de banca, no burburinho e nos debates mais amplos" (p. 101).

Os fazeres das trabalhadoras atuantes em abatedouros também possuem essa articulação com o chão do cotidiano, assinalada por Sato (2007). As redes envolvem as negociações com clientes, vizinhos, inspetores da vigilância sanitária, entre outros. "É que nem ontem, eu puxei [busquei] todos os animais, pois nós matamos cinco. Eu fui buscar um porco grande, fui buscar sozinha e a mulher me disse: 'tu és louca', mas eu não tenho problema com isso" (Valéria). As três trabalhadoras entram em contato com outras pessoas, tanto no recolhimento dos animais, como na comercialização; elas participam e interagem com essa rede de produção.

Na realidade investigada, também foi possível compreender um cuidado familiar, não que o trabalho das mulheres fosse menos exigente no âmbito familiar rural do que em outro espaço produtivo, pois as mulheres trabalham muito e continuadamente mostrando a nítida presença da divisão sexual do trabalho na propriedade familiar rural. O cuidado foi observado com alguns procedimentos produtivos, possíveis causadores de riscos à saúde dos trabalhadores que em outros contextos laborais não haveria, tal como apontado por Valéria: "Só não pico [a carne] porque o pai tem medo que corte a mão, só não corto carne" (Valéria).

Cristina e Valéria exerciam todas as atividades relacionadas à produção, como também a limpeza e a conservação do ambiente efetuadas aos finais de semana. Helena, além das atividades de limpeza, conservação e execução dos cortes da carne, também exercia atividades administrativas. Ao longo de toda a entrevista, ela ressaltou o exercício de atividades gerenciais do estabelecimento, relacionada à administração financeira e comercial do negócio. Um exemplo foi quando o marido queria comprar uma caminhonete, mas na época a família não possuía todo o valor, foi ela quem negociou o parcelamento da dívida.

Apesar das similaridades, as vivências e incursões pelas atividades efetuadas no abatedouro foram desenvolvidas diferentemente por cada uma das mulheres entrevistadas. Dubar (1998) esclareceu que as identidades profissionais são constituídas a partir dos cotidianos de trabalho exercidos pelos sujeitos, com uma estreita aproximação entre "o mundo da formação" e o "mundo do trabalho ou emprego". Foi possível compreender, a partir dos relatos, que foi Helena a trabalhadora com mais alternativas de trabalho dentro do abatedouro, no entanto, a maior parte do trabalho feito pelas três mulheres era caracterizado pelo trabalho doméstico reprodutivo e não remunerado. 


\section{Análises das trajetórias ocupacionais: pensar o futuro}

Quanto aos discursos das entrevistadas sobre o futuro, foram observados dois aspectos: um futuro próximo como continuidade dos seus afazeres e outro como um anseio longínquo. Pensar o trabalho no futuro aqui é compreender que este é "... marcado pelas contradições do passado e do presente e pelas possibilidades de cada um ressignificar os sentidos produzidos ao longo de suas trajetórias identitárias" (Coutinho, 2009).

Cristina afirmou que gostaria de trabalhar em uma padaria, mas precisa dar continuidade ao trabalho no abatedouro: “... gostava de ser padeira, fazer doces, bolos, essas coisas. Mas já que ele [o marido] tá aqui, tem que acompanhar, né? [risos]” (Cristina). Valéria narrou seu desejo de permanecer no abatedouro: "Meu Deus, aqui é melhor, eu gosto daqui, [...] porque se um dia o pai morrer eu continuo", mas também relatou seu sonho, "Meu sonho, eu gostaria de trabalhar como frentista de posto. Que eu gosto de carro, moto, essas coisas. Sou viciada nisso, eu gostaria... mas não ganha bem, né?" (Valéria). Helena descreveu que gostaria de trabalhar na área administrativa de um abatedouro de coelhos que será construído na localidade onde mora, mas sem deixar de cuidar da área administrativa do seu estabelecimento.

Assim como o ingresso das entrevistadas na atividade foi relacionado com atividades familiares, as expectativas de atividades profissionais futuras também se mostraram marcadas pelo contexto familiar. Houve uma articulação entre o projeto pessoal das mulheres com o projeto familiar, não existindo uma significativa separação. Fato também identificado por Graf e Diogo (2009), quando analisaram as projeções de futuro de jovens, em que os rapazes almejavam maiores projeções econômicas, enquanto as moças pensavam no futuro profissional articulado com vivências familiares.

\section{Considerações finais}

Este artigo objetivou compreender as trajetórias ocupacionais de três mulheres do contexto da pequena produção de carne. Compreendendo as estratégias de investigação das trajetórias no trabalho, tal como concebem Dubar (1998), Gaulejac (2005), bem como das trajetórias identitárias de Coutinho (2009). A análise das trajetórias das entrevistadas contribuiu para a compreensão de sua vida laboral, considerando passado, presente e futuro, bem como outros fatores que envolvem a vida e o contexto dos sujeitos de pesquisa. Nos discursos das trabalhadoras, foi possível compreender os movimentos temporais organizados nas três categorias temáticas, não excludentes, mas entrelaçadas, possibilitando maior compreensão sobre as vivências profissionais das trabalhadoras em um contexto de produção de carne.

No olhar para o passado, os resultados mostraram a entrada gradual das trabalhadoras na atividade de abate, por esta atividade já ser exercida no âmbito familiar. Não houve estranhamentos em participar da atividade, mesmo porque adentraram o mundo do trabalho a partir das práticas de abate e de outras de cultivo agrícola. Outro aspecto importante, evidenciado nos relatos das entrevistadas, foi o limitado acesso que tiveram a empregos formais, sendo que estas oportunidades eram marcadas por condições precárias e baixa remuneração.

No caminhar no presente, o contexto atual do trabalho das entrevistadas foi destacado pela importância de serem proprietárias. A ação dessas mulheres foi significativa na construção dos abatedouros, tanto que suas vivências se confundem com a própria história dos estabelecimentos. Os dois estabelecimentos possuem em seu bojo marcas da ruralidade e um processo inicial de industrialização, revelando as dificuldades e as contradições das trabalhadoras ao deixarem de ser apenas agricultoras para tornarem-se industriais e sócias de 
estabelecimento comercial. Outro ponto importante foi o tema da escolaridade, a falta de acesso à educação gerou diminuição das possibilidades de trabalho dentro da própria atividade produtiva. Natividade (2006) assinalou o quanto as crianças já apresentam a formulação de um projeto profissional, de modo que a concepção de trabalho já está inserida na realidade das crianças, bem como o discurso capitalista sobre o trabalho.

Por meio da análise das vivências no cotidiano laboral das entrevistadas, foi possível identificar positividades e negatividades (Coutinho, 2009). A positividade foi associada ao fato de serem proprietárias de seus próprios trabalhos, não havendo superiores, controle de atividades, bem como o fato de as pessoas da família cuidarem para haver diminuição de acidentes no trabalho. As negatividades podem ser relacionadas à necessidade de contínuas adequações no estabelecimento, tomando parte considerável dos recursos financeiros da família e pelas mulheres necessitarem realizar simultaneamente as atividades produtivas e reprodutivas.

Quanto ao pensar o futuro, houve uma marca de continuidade entre a atividade produtiva da carne junto com os familiares e outras, que quase se assemelhavam a um sonho muito distante da realidade. Essas projeções de futuro se aproximaram do estudo de Graf e Diogo (2009), com o enfoque de gênero, no qual apontaram que os projetos profissionais de mulheres possuem maior envolvimento com as relações familiares do que os projetos dos homens. Longe de esgotar as questões relativas ao trabalho de mulheres na produção de carnes, este artigo é uma contribuição ao estudo das trajetórias nesse setor produtivo. Como apontado no contexto da pesquisa, sobre a produção de carne, é necessário compreender não somente os trabalhadores das grandes organizações, mas também das pequenas e das médias empresas que abrangem, pelas informações do IBGE, mais de $80 \%$ dos estabelecimentos brasileiros.

\section{Referências}

Alves, J. A. (1991). O planejamento de pesquisas qualitativas em educação. Cadernos de Pesquisa, 77, 53-61.

Associação Brasileira de Frigoríficos (2008). Pecuária de corte: SC quer autosuficiência em carne bovina. Recuperado em 28 de maio e 2008, de www.abrafrigo.com.br

Bruschini, M. C. A. (2007). Trabalho e gênero no Brasil nos últimos dez anos. Cadernos de Pesquisa, 37 (132), 537. 572).

Cazella, A. A. \& Alves, A. F. (2004) A multifuncionalidade agrícola em zonas rurais contrastantes. In M. I. S. Paulilo \& B. W. Aued (Orgs.), Agricultura familiar. Florianópolis: Insular.

Classificação Nacional de Atividades Econômica (2006). Instrumento de padronização nacional dos códigos de atividades econômicas. Recuperado em 21 de julho de 2008, de www.receita.fazenda.gov.br

Coutinho, M. C. (2009). Sentidos do trabalho contemporâneo: as trajetórias identitárias como estratégia de investigação. Cadernos de Psicologia Social do Trabalho, 12 (2), 189-202.

De Grandi, A. B. de (2003). Relações de gênero em famílias agricultoras em Santa Catarina. In M. I. S. Paulilo \& W. Schimdt (Orgs.), Agricultura e espaço rural em Santa Catarina (pp. 39-70). Florianópolis: UFSC.

Decreto Lei 3.748 (1993, 12 de julho). Regulamento da Inspeção Industrial e Sanitária de Produtos de Origem Animal. Diário Oficial do Estado de Santa Catarina. Recuperado em 22 de julho de 2008 de http://www.cidasc.sc.gov.br

Demazière, D. \& Dubar, C. (2006). Trajetórias profissionais e formas identitárias: uma teorização. In N. A. Guimarães \& H. Hirata (Orgs.), Desemprego: trajetórias, identidades, mobilizações (pp. 167-187). São Paulo: Senac.

Dubar, C. (1998). Trajetórias sociais e formas identitárias: alguns esclarecimentos conceituais e metodológicos. Revista Educação $\mathfrak{E}$ Sociedade, 19 (62), 13-30.

Embrapa Gado de Corte. (2007). Embrapa Gado de Corte comemora 30 anos. Banco de Notícias Embrapa Gado de Corte. Recuperado em 11 de junho de 2008 de http://www.cnpgc.embrapa.br 
Ferraz, J. V. \& Figueiredo Jr., G. (2003). Serviço de Informação da Carne- SIC. Produção de carne. Site corporativo. Recuperado em 20 de junho de 2008 de http://www.sic.org.br/producao.asp

Florit, L. F., Teixeira, V. I., Chaves, I. M. \& Graf, L. P. (2006). Interesses de humanos e de não humanos nos abatedouros do Médio Vale do Itajaí. Relatório Final Técnico Científico. Edital Cidadania. Convênio FAPESC/ FURB. [mimeo]

Gaulejac, V. de (2005). O âmago da discussão: da sociologia do indivíduo à sociologia do sujeito. Revista Cronos, 5/6 $(1 / 2), 59-77$.

Graf, L. P. \& Diogo, M. F. (2009). Projeções ocupacionais juvenis: visões entretecidas com as marcas de gênero. Revista Brasileira de Orientação Profissional, 10 (1), 71-82

Graf, L. P. \& Silva, C. A. F. (2006). Amélias condenadas ao inferno: estudo de mulheres trabalhadoras em um pequeno abatedouro no Médio Vale do Itajaí (SC). Monografia de Especialização, Curso de Pós-Graduação em Gestão e Educação do Trabalhador, CEUNI, Blumenau.

Goularti Filho, A. (2007). Formação econômica de Santa Catarina (2ª ed. rev.). Florianópolis: UFSC.

Hirata, H. (2002). Nova divisão sexual do trabalho? Um olhar voltado para a empresa e a sociedade. São Paulo: Boitempo.

Instituto Brasileiro de Geografia e Estatística (2004). Resultados da Amostra do Censo Demográfico 2000: malha municipal digital do Brasil, situação em 2001. Rio de Janeiro: IBGE.

Instituto Brasileiro de Geografia e Estatística (2008a). Indicadores IBGE. Estatística da Produção Pecuária. Julho de 2008. Recuperado em 21 de junho de 2008 de http://www.ibge.gov.br

Instituto Brasileiro de Geografia e Estatística (2008b). Pesquisa Mensal de Emprego. Suplemento Mulher: algumas características da inserção das mulheres no mercado de trabalho em Recife, Salvador, Belo Horizonte, Rio de Janeiro, São Paulo e Porto Alegre 2003-2008. Rio de Janeiro: IBGE.

Kassouf, A. L. (2007). O que conhecemos sobre o trabalho infantil? Nova economia, 17 (2), 323-350.

Lei no 1.283 (1950). Dispõe sobre a inspeção industrial e sanitária dos produtos de origem animal. Diário Oficial da União, 1, 1816

Natividade, M. R. (2007). O trabalho na sociedade contemporânea: os sentidos atribuídos pelas crianças. Dissertação de Mestrado, Departamento de Psicologia, Universidade Federal de Santa Catarina, Florianópolis.

Ney, M. G. (2006). Educação e desigualdade de renda no meio rural brasileiro. Tese de Doutorado, Instituto de Economia, Universidade Estadual de Campinas, Campinas.

Paulilo, M. I. S. (2004). Trabalho familiar: uma categoria esquecida de análise. Revista Estudos Feministas, 12 (1), 229-252. Florianópolis.

Paulilo, M. I. S. \& Aued, B. W. (2004). Prefácio. In M. I. S. Paulilo \& B. W. Aued (Orgs.), Agricultura familiar. Florianópolis: Insular.

Paulilo, M. I. S. \& Schmidt, W. (2003). Apresentação. In M. I. S. Paulilo \& B. W. Aued (Orgs.), Agricultura e espaço rural em Santa Catarina. Florianópolis: UFSC.

Regulamento da inspeção industrial e sanitária de produtos de origem animal [RIISPOA]. (n.d). Aprovado pelo Decreto $n^{\circ}$ 30.691, de 29-03-52, alterado pelos Decretos no 1.255 de 25-06-62, 1.236 de 02-09-94, no 1.812 de 08-02-96 e no 2.244 de 04-06-97. Recuperado em 01 de agosto de2008 de http:/www.agricultura.gov.br

Sarcinelli, M. F., Venturini, K. S. \& Silva, L. C. da (2007). Produção de Bovinos: tipo carne. Boletim Técnico PIEUFES: 00307. Universidade Federal do Espírito Santo. Recuperado em 21 de julho de 2008 de http://www.agais.com/telomc/b00307_carne_bovinodecorte.pdf

Sato, L. (2007). Processos cotidianos de organização do trabalho na feira livre. Psicologia $\mathcal{E}$ Sociedade, 19 (número especial), 95-102.

Soares, D. H. P. \& Sestren, G. (2007). A trajetória socioprofissional. In M. Lima \& D. Barros (Orgs.), Orientação profissional: teoria e técnica (vol. 3, pp. 81-96). São Paulo: Vetor.

Stolf, M. C. (2007). Os sentidos atribuídos por agricultores às tecnologias utilizadas em seu cotidiano de trabalho. Dissertação de Mestrado, Departamento de Psicologia, Universidade Federal de Santa Catarina, Florianópolis.

Stropasolas, V. L. (2006). O mundo rural no horizonte dos jovens. Florianópolis: UFSC. 
Zago, N. (2003). A entrevista e seu processo de construção: reflexões com base na experiência prática de pesquisa. In N. Zago, M. P. Carvalho \& R. A. Teixeira (Orgs.), Itinerários de pesquisa: perspectivas qualitativas em sociologia da educação. Rio de Janeiro: DP\&A.

\section{Endereço para correspondência}

lailagraf@gmail.com

Recebido em: 15/12/2008

Revisado em: 09/07/2009

Aprovado em: 11/07/2009 